\title{
Gearing up education towards Industry 4.0
}

\author{
Krishnan Umachandran, Igor Jurčić \\ , Debra Ferdinand-James, Mohamed MohamedTolba Said, Adnan Abd Rashid \\ Nelcast Ltd., India Mostar University, Bosnia and Herzegovina \\ The University of the West Indies, Trinidad IIUM, Malaysia
}

\begin{abstract}
Industry has changed creatively with manufacturing systems and technological applications supplementing in the work preparation, reporting variants, methods and resources for effective production management by constant improvements and usage has matured it way to Industry 4.0. Industry has undergone various revolutions up to now, and through cyber-physical systems would communicate, collaborate in real time of the process and product value stream. Technology upgrades will bring optimization in various resource utilization and focus on satisfying customers even over their ever increasingly demand. The gadgetry conveniences would bring the wearable's and embedded handle large databases for dynamic mining and interpretations obsoleting the necessity of strain in carrying laptops or pads. Innovation would be successful as it facilitates quick product developed self-customized for use at the shortest development time. Studentcentered learning, learning consequences will have lifelong erudition where educational institutions will develop robust integrated systems and infrastructure to facilitate learning by doing rather than by the conventional learning. New age of Industry 4.0 will bring in a considerable change in physical world as in the virtual facilitation enabled by digital connect shrinking the distances, removing differences, and conducting real time transfer knowledge and material transfer globally. Being technologically prepared is the need of the time then to wait for the opportunity to push the educational system to change, where the time loss would handicap the economy and younger generations to be forced to compete even with perceived incapable and smaller frugalities.
\end{abstract}

Keywords - IIoT, IoE, ICT, Industry 4.0, Digital age, Employable skills, InternetTechnologies

Language: English

Date of Publication: 21-09-2018

DOI: $10.24297 /$ ijct.v17i2.7754

ISSN: 2277 - 3061

Volume: 17 Issue: 02

Journal: International Journal Of Computers \& Technology

Website: https://cirworld.com

This work is licensed under a Creative Commons Attribution 4.0 International License. 


\section{Introduction}

Industry 4.0 is intensive implementation of industrial practice across different areas of organization's operations and aided by IT systems to facilitate quick decision making for improved productivity and quality (DariuszPlinta., 2016).Digital and Smart Factory 4.0 are part of the global changes in the manufacturing industry developmental paradigm Industrial 4.0.Industry has evolved innovatively with production systems and technology implementations assisting the work in preparation and reporting of technical documentation on product variants, methods and resources. The rational step of Industry 4.0 implementation exerts to instigate and resonate across various countries directing large investments towards $10 T$ in products and $I I O T$ in processes, which will catalyst a rapid growth in smart consumerism of the market.Industry has transformed ingeniously through engineering methods and hitech applications complementing in the effort to initiate, convey alternatives, approaches, asest and means for operative fabrication execution and continuous enhancements in practice that can season its mode to Industry 4.0. This support was for facilitating the acceleration production cycles, new products and processes development, minimization of the supplies level, more efficient logistics, and the usage of effective and innovative ideas of production realization through Lean Production, JIT (Just in Time), Total Quality Management, and Digital Factory. These methods allow for effective production management by constant improvements and usage of different automated tools facilitated by technology (DariuszPlinta., 2016).Industry 4.0 is built on four basic points, the production system, integration value chain network, production flow and facilitating SMART Technologies; all these characterizes and distinguishes it from traditional production process (MiroslavMindas., SlavomirBednar., 2016). Industry 4.0 is alter ego named as a learning factory with its pivotal role in helping to develop the creative content, collaborate resources, communicate machine to machine and machine to men, and being innovative by globally aware of the required high and relevant digital literacy to keep pace with the changes in the digital industrial world that offers vast opportunities, for timely demand on crucial precision actions that are required to handle uncertainties (S.M Sackey., A. Bester., D. Adams., 2017). Industry has experienced numerous upheavals time and again and has evolved to a position to use the cyber-physical systems for interconnected, collaboration and integration in a real time with the processes towards value addition of product performance. Industry 4.0 includes the following robots, simulators, Integration software, Industrial Internet of Things -IIoT, Inter communication between machines, Internet of Services, Big data analytics, data sciences, Cloud infrastructure, 3D printing, Augmented and Virtual Reality, Cyber-Physical Systems, Artificial Intelligence, and Mass Customization. Digital Factory is an integration chain between CAD systems and ERP solutions where deployment of planning, simulation and optimization techniques in manufacturing of highly sophisticated products (DariuszPlinta., 2016). Government's incentivize massive investments and loan approvals amounting to several billion of US \$ for various companies; which showcase the strength of a nascent adaptation coming into fruition. From the moment of entry up to transformation, Industry 4.0 brings encouraging prospect for SMEs along the stages of technological integration for the sector. Industry has undergone various revolutions such as the initial agrarian; inventions along with steam power and mechanical drives; electric power with electronic controls including the computer enabled modernizations; and now the cyber driven robotics, artificial intelligence and Internet of things. Therefore, the Industry 4.0 is revolutionized with cyber-physical systems which communicate, collaborate in real time of the value stream (DariuszPlinta., 2016). In energy-intensive industries, energy costs form a significant part of the operation costs, using IoT and predictive analytic technologies can reduce energy consumption and operating costs significantly.Industry 4.0 has a crucial role on the technologies that are involved in the curricula evolution, development and implementation (S.M Sackey., A. Bester., D. Adams., 2017). Expertiseand renovationsshould conveythe benefit of improved output over several resource operations and emphasis on nourishingconsumers even with their continualprogression in demand. Technology upgrades will bring reduction in time to market, cost reduction, generate real NC-part programming in machining centers, machine visualization and operations, design of experiments, material-information-value-financial flow simulation and optimization, layout markings and inventory reductions, value addition in supply chain logistics, ergonomic analysisand man-machine interactions, and robotics systems optimization (DariuszPlinta., 2016).The equipment's and tool which are the amenitiesto facilitate work includes the wearables and also as implantedto facilitate huge databases aimed atactivequery and analysesthus rendering the physical 
requirement of carrying gadgets. Integrated systems consist of systems which carry out product design, process planning, process design validation, production engineering, planning control, automation and process control (DariuszPlinta., 2016).Innovation isfruitful as it enablesfast product development with selfdirected usage at the quickest possibleprogression of time. Learner-centered and self-enabled learning concerns will require the universities and institutions to advanceinto a strongincorporatedorganizations and infrastructure which enableknowledgeshare by practice orientations rather than through the orthodox learning. Perceptions of enterprise is the most critical resource that can extend well beyond its specific boundaries and can be shared with partners from a dyadic alliance with analyses related towards strategic networks (Della Corte V., Sciarelli M., 2012). Customers ever increasingly demand for shortest time of need satisfaction, brings complex pressures in production (MiroslavMindas., SlavomirBednar., 2016). An innovation is successful, only when the product developed has the shortest development time ie., quickly to reach the market when launched. Product development requires close collaboration in production planning, controlling, chaos handling and supplementary costs (DariuszPlinta., 2016). Industry 4.0 connects and cooperates effectively, with very close links between suppliers, manufacturers and customers (MiroslavMindas., SlavomirBednar., 2016). By dispensing game changing innovations like Intelligent Automation, Internet of Things, Cyber-Physical Production Systems, Cloud and Robotics, the manufacturing industries have the potential to become a beacon for Smart-infused factories

Figure - Benefits of Industry 4.0

\section{Productivity}

- Solutions to eliminate errors and wastage

- Produce more products

- Shortened cycle times

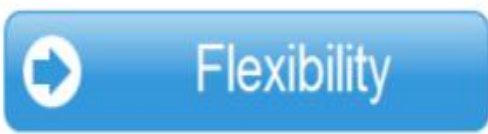

- Personalised products

- Efficient production

- Large variability in production control

\section{Safety}

- Software prevents defects

- Sensors are protecting worker safety

- Immediate reaction
- The advantages of mass production

- Optimized processes

- Low stock inventories

- Production efficiencies

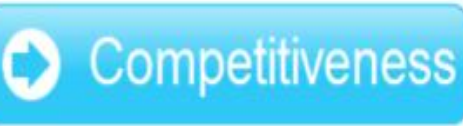

- Low manufacturing costs

- Use of innovative

solutions

- Flexible response to

fluctuations of demand

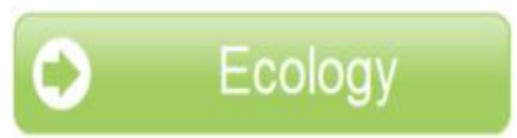

- Switching off unused objects

- Use of green solutions

- Renewable energy

Source - Miroslav et al., (2016).

The Industry 4.0 will prove advantageous to small and medium-sized organization and facilitate easy operation in overseas markets, using cloud computing storage for Big Data and develop opportunities in B2B development (MiroslavMindas., SlavomirBednar., 2016). Industry 4.0 should work and acknowledge those potentials in transforming the industry with the latest knowledge and insights for becoming part of the transformation under educational facilitation. Industry 4.0 is pull driven and asynchronous manufacturing system driven by customer requirement, to produce digitized elements of industrial systems, with IT support technologies for precise specifications of small-lot production, to serve customized requirements, thereby supporting them on handling business uncertainty risks (MiroslavMindas., SlavomirBednar., 2016). To avoid 
risks cyber security, must start form planning stage and mitigate the risks that Industrial IoT devices be designed for greater security and steadily integrated into prevailing automation and information system architectures.To promote the inclusion of industry 4.0 practices and to benefit in higher education, encouragement in the development of suitable studies and technology enabled surveys to assess, shall quantify and communicate the economic and social benefits of the innovation in education (ESS., 2010).Educational institutions should offer courses at the required time to ensure relevance with technological demands, therefore as robotics and artificial intelligence replace tradition activities through computerized environment; such courses need to be included into the curriculum. Global educational curriculum should effectively report the essentials of specific businesses and their IT capability to future technology in information, communication and embedded computing in Automation, robotics and Artificial intelligence (AI) to meet consumer expectations, before becoming obsolete (Krishnan Umachandran.,Valentina Della Corte., Mohamed MohamedTolba Said., 2018). Industry 4.0 are more fault-tolerant, while capable of producing with maximum efficiency (MiroslavMindas., SlavomirBednar., 2016). Merchandising has already touched new heights with agile supply chain and logistics, moved away from conveniently to online purchasing and financial transactions with anywhere reach. The student-centered learning should go through learning consequences with lifelong erudition for the use of ICT in education by radically novel approaches to facilitate learning. Curricula and programs are barely in line with the industry expectations and social life. With countries approaching in the direction of becoming an ideal one towards development, and with the nexus of high human development index, the highly industrialized economy can only become the prime mover for the economical embellishment.Data science in an information work space for data analytics requires processing through scores, prediction of cross- field inputs, and functional algorithms, thus results in a data warehouse where appropriate intelligence tools are used for decision-making (Umachandran K., Ferdinand-James D., 2017).

\section{Demand on Education}

Economic growth and contribution to international society through ICT will be the demanding factors that would reflect a country to become more active in the global sphere (Hishida, Mitsuhiro.,2015). New age of Industry 4.0 determines to convey substantial alterations in the physical ecosphere as in the cybernetic assistance by permitted digital connect reducing the spaces, eradicating variances, and steering universally the material transfer along with knowledge on a real time basis. To gauge the Smart technology for manufacturing process across various regions and adapt Industry 4.0 in manufacturing sector by aligning with the education. Educational institutions should examine multiple entry points for Industry 4.0, provide relevant education and training opportunities and expose them (European Commission., 2017), to the necessary adaptation and conceptualize cost-effective method of adaptation that result in high productivity to expound the economies of scale.The outbound development (products/process) will become demanded customizations as per customer needs and the innovation with mass coverage will have wider spread implications. The increased productivity or the increase in output is not due to an increase in the direct inputs used to produce goods and services but due to the influence of technology (Foresight.,2013) which scales the pace of delivery with quick decision making process. Developments in manufacturing operations are becoming archaic in healthcare, consumables, food and domestic activities.Integrated conservation and development programs with data inputs Industry 4.0 can become a favored policy tool to possibly endure growth and concurrently, progress the welfare of communities by facilitating alternative livelihoods to farmers. All specialization to suit human requirements shall be produced in mass scale. 
Figure 1- Rolling mass of change demands on higher education

\section{Demands on higher education}

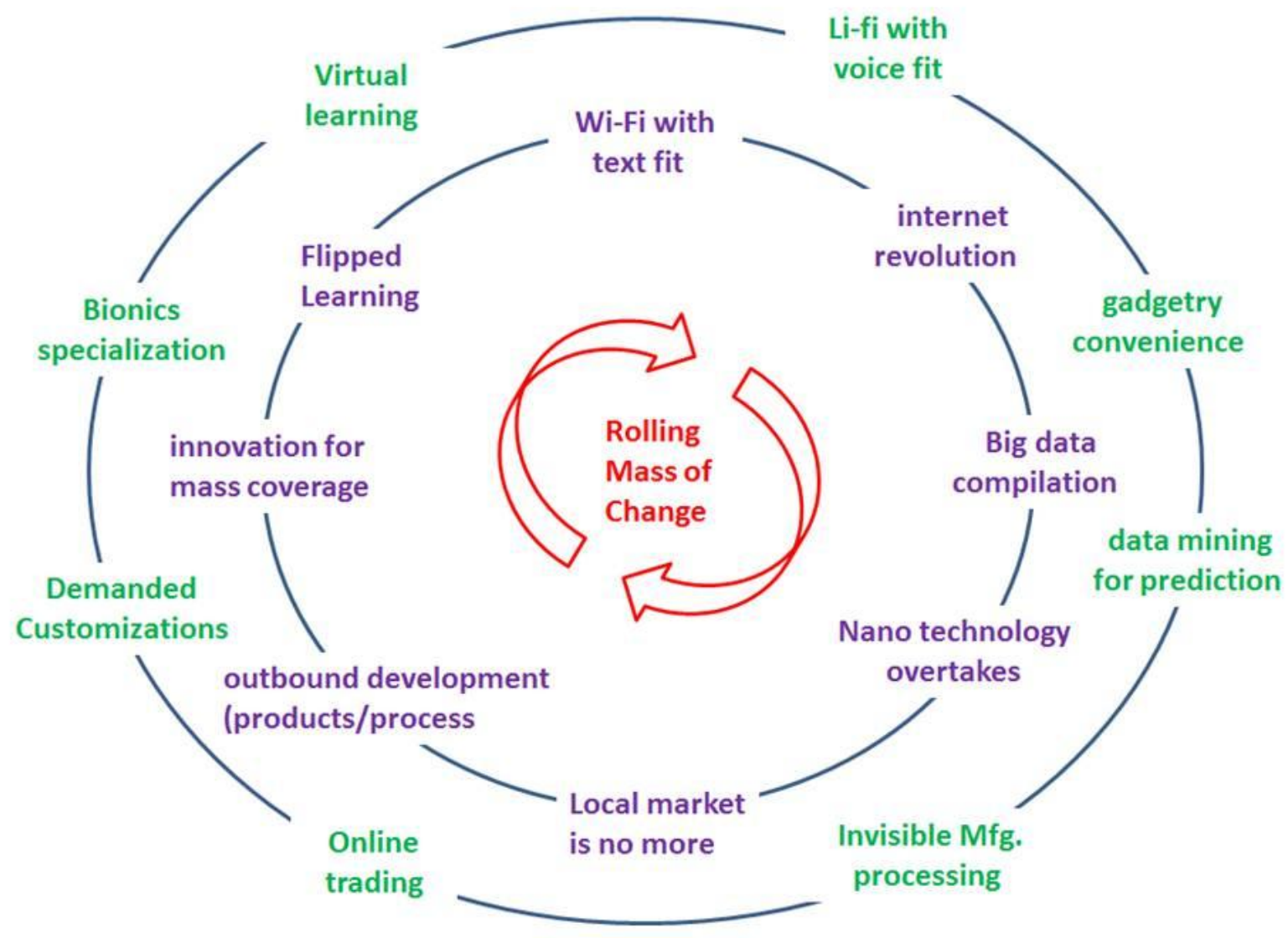

Source - Umachandran. K., (2018)

The rolling mass of change, as in Figure 1 , would have bearing with a great bang on demands in higher education. The radical impact of technology will leap from the existing state, where the higher education is yet to revoke from its initial impact of knowledge revolution. The arrival of light fidelity will web the world with internet connectivity all time, throughout sunlight availability during the day and LED lights during the nonavailability of daylight. The key to student's engagement in participatory learning of facilitating reading experience through text based learning will be many time multiplied many a times with voice based learning through light packets of Li-fi facilitation, removing the current hurdle of data bandwidth and interruptions. When the resources are available in plenty, the opportunity to learn is in explicable and in all forms to reach as a universality to humankind. Cloud computing system with streaming technology connects clients and computing resources, the server virtualization can achieve better physical resource utilization and high performance storage thereby enabling simulations and client QoS (Krishnan Umachandran.,Valentina Della Corte., Mohamed MohamedTolba Said., 2018).

The gadgetry would become convenient, initially as wearables, later would evolve to become embedded, for examining large pre-existing databases to create renewed information, without the physical strain of carrying the laptops or pads. Thereby the learning access tends to relate past experience to future ones in order to improve the knowledge base according to their needs for learning processes independent of location and the process of resource replication through reciprocal learning help to acquire those valuable, rare and inimitably related skills and competences(Della Corte V., Sciarelli M., 2012). With changes in manufacturing process from conventional to non-traditional novel process such as nanotechnology, the identity of materials and their utilization is expected to vary completely. Widening the manufacturing value chain requires flexible stretch of 
the production process where raw materials are transformed into physical products through processes comprising people its associated systems (Foresight.,2013).Creating new value-added industries; solving social problems; improving and strengthening a common ICT basis can be the parameters for visioning a growing economy (Hishida, Mitsuhiro.,2015). Pedagogy should focus on to discover the full potential of Industry 4.0 and its application to enhance manufacturing through Smart Factory, recognize the challenges and pain points during various level of technological integration through active deliberations with industry experts and specialist on ways to orient the mindset of farm enterprise employability requirements. Industry 4.0 deployment needs new skills that will change or might even make the existing redundant and replace with autonomous robots.Customer preferences are highly demanding with made-to concept evolution to suit individual preferences and requirements. Growth gets limited only by creativity blocks, hence to overcome and become competitive, businesses embrace new IT delivery models such as SaaS, PaaS, and agile to control costs and increase agility by tapping into data which are completely new or that was never before known earlier. Customized dynamic decisions with intelligence of no perceived boundaries are now possible with big data analytics(Umachandran K., Ferdinand-James D., 2017).

\section{Evolving new business}

The new era of manufacturing is evolving to be marked by highly agile, application of leading-edge technical knowledge integrated and self-morphing resource talents are necessary to effectively apply cutting edge in science and technology systems of smart services and process excellence (Foresight., 2013).Industry 4.0 aims to create new products and services, define new business models that could differentiate the competing market players by improving of customer experience through potential services and the role of telecommunication in them (I. Jurčić, K. Umachandran, V. Della Corte, G. del Gaudio, V. R.Aravind, D. Ferdinand-James., 2018). Medical innovations have moved to artificial culturing and development of replaceable body parts and supports to improve longevity and health improvements in the historical annals of mankind. Higher learning has already evolved from lecturing system to flipped learning concept, which would still be continued to be reborn with more facets with the support of virtual learning in the days to come. Data is the significant component in the farm segment to be more prolific, justifiable and endure competition in a comprehensive setting. Educational institutions that dare to risk for moving towards innovatively accommodate industry 4.0 are ending to a catastrophe in supply of people resources to the modern industries. The use of sensors and universalization of control systems on interconnected individual farm devices consume a great stretch on application due to technological maturity and innovative improvements for a superior optimization potential accessible through data procedures. Development is going to be continuous and the only limitation to it is the creativity block. Higher education is already losing the course concentrations of core specializations to inter/multi disciplines, which will eventually become hybrid specializations.This exciting development will further spur the interest of the SME enterprises, prompting encompassing adaptation to move up the value chain in becoming front-end manufacturer's feasibility to become Industrial 4.0 compliant. Industry 4.0 covers progressive analytics, innovative human-machine touch points, digital-to-physical assignment knowledge, and information communication systems are needed to meet the challenges with educational facilities meticulously similar to real-life setups that are capable towards delivering actual and effectual coaching (S.M Sackey., A. Bester., D. Adams., 2017).

\section{Conclusion}

The education sector, unlike other service sectors, is a bit slow not in responding to changing needs of the education market (Umachandran K., Ferdinand-James D., 2017).Existenceof technological support needs to be prepared ahead of the required moment. Opportunity loss would heavily burden the educationsystem and would impinge the change requirements as a lost time leading the disrupting the advantageous economy and straining thefuturegenerations. The volume of data captured by businesses with advancements in multimedia, social networking and the IoT will fuel future increases in data, allowing organizations to grow in line with customer likings and customize its products (Foresight.,2013).Institutions that fail to educate their students on these new technologies and capitalize on research projects will miss their advantage and opportunity that 
could lead to the transformation presently comprehensive traversing the manufacturing industry. The industry 4.0 educational concept should step towards learning factory with specifies that needs to be learnt, process with which it needs to be learnt, and by competent facilitator to the process of learning with necessary content after capacity building (S.M Sackey., A. Bester., D. Adams., 2017). Student-centered learning facilitated by educational institutions developsintegrated systems and infrastructure that enable knowledge and skills development by more of practice orientations than through the conventional methods. The new manufacturing age of Industry 4.0 purposes to change the physical world with virtual facilitation by digital bond attenuating the distances, eliminating differences, steering real time worldwide transmission of information and material transactions.

\section{References}

1. DariuszPlinta., (2016), New information technologies in production enterprises, Advanced -industrial engineering, Industry 4.0, Bielsko-Biała, pp. 7-20.

2. MiroslavMindas., SlavomirBednar., (2016), Mass customization in the context of industry 4.0: implications of variety induced complexity, Industry 4.0, Mass customization, Complexity, Demand, Variety, Advanced industrial engineering, Industry 4.0, pp.21-39.

3. S.M Sackey., A. Bester., D. Adams., (2017), Industry 4.0 learning factory didactic design parameters for industrial engineering education in South Africa, South African Journal of Industrial Engineering, Vol 28(1), pp. 114-124

4. Umachandran K., \& Ferdinand-James D., (2017), Affordances of Data Science in Agriculture, Manufacturing, and Education (Chapter 2). In SharvariTamane (Ed.), Privacy and Security Policies in Big Data, PA, USA: IGI Global.

5. Foresight., (2013), The future of manufacturing: A new era of opportunity and challenge for the UK: Summary Report, The Government Office for Science, London.

6. European Commission., (2013), Factories of the future - Multi-annual roadmap for the contractual PPP under Horizon 2020, https://www.scribd.com/document/271903700/Factories-of-the-Future-2020Roadmap\#

7. Della Corte V., Sciarelli M., (2012), Cancoopetition be source of competitive advantage for strategic networks? Cooperate Ownership \& Control, 10(21), 363-379.

8. Krishnan Umachandran., (2018), Rolling mass of change, Innovation project, https://www.researchgate.net/project/Innovation-70/update/5aa6077b4cde266d5890c3d5

9. Hishida, Mitsuhiro., (2015), Japan: Smart Japan ICT Strategy, Internal Affairs Ministry, https://www.crcom.gov.co/recursos_user/Documentos_CRC_2015/Eventos/10taller/10Hishida.pdf

10. ESS., (2010), Report of the export panel for the review of the europeanstandandard system : Standardization for a competitive and innovative Europe: a vision for 2020", February 2010, pp.45, http://www.anec.eu/attachments/Definitive\%20EXPRESS\%20report.pdf

11. European Commission., (2017), High-Tech Leadership Skills for Europe, pp.132, http://eskillsscale.eu/fileadmin/eskills_scale/all_final_deliverables/scale_e-leadership_agenda_final.pdf,

12. Jurčić, K. Umachandran, V. Della Corte, G. delGaudio, V. R. Aravind, D. Ferdinand-James., (2018): Industry 4.0: Unleashing Its Future smart Services, CIET 2018, Split, Croatia.

13. Krishnan Umachandran.,Valentina Della Corte., Mohamed MohamedTolba Said., (2018), Innovation in business development, In the book by Anna Cierniak-Emerych, SzymonDziuba, AgataPietroń-Pyszczek, AndrzejBodak., (2018), Enterprise and human resource management as areas of innovations, Edition: 1, Chapter: 1, Publisher: OficynaWydawniczaStowarzyszeniaMenedżerówJakościiProdukcji. Al. Armiikrajowej 19b lok. 504z, 42-218 Częstochowa, 